\title{
Annular Pancreas: A Rare Cause of Duodenal Obstruction in Adults
}

\author{
Devi Prasad Patra • Abhimanyu Basu • \\ Amit Chanduka $\cdot$ Amit Roy
}

Received: 4 April 2010 /Accepted: 26 October 2010 /Published online: 16 November 2010

(C) Association of Surgeons of India 2010

\begin{abstract}
Annular pancreas is an uncommon congenital anomaly which usually presents itself in infants and newborn. Rarely it can present in late adult life with wide range of clinical severities thereby making its diagnosis difficult. Pre-operative diagnosis is often difficult. CT scan can illustrate the pancreatic tissue encircling the duodenum. ERCP and MRCP are useful in outlining the annular pancreatic duct. Surgery still remains necessary to confirm diagnosis and bypassing the obstructed segment.We report a case of 61 year female presenting with duodenal obstruction due to annular pancreas.
\end{abstract}

Keywords Annular pancreas · Adults · Duodenal obstruction

\section{Introduction}

Annular Pancreas is a rare congenital anomaly which consists of a ring of pancreatic tissue partially or completely encircling the second part of the duodenum. Though it accounts for around $1 \%$ of all intestinal obstructions in paediatric population, it rarely presents itself in adults [1].

\section{P. Patra $(\square)$}

Department of General Surgery, Junior Doctors Hostel,

SSKM Hospital, IPGME\&R,

Room No. 545, AJC Bose Road,

Kolkata 700020, India

e-mail: devosy4ever@yahoo.co.in

A. Basu $\cdot$ A. Chanduka $\cdot$ A. Roy

Department of General Surgery, SSKM Hospital, IPGME\&R,

AJC Bose Road,

Kolkata 700020, India

\section{Case Report}

A 61 year female presented with 3 months history of postcibal distention of upper abdomen and vomiting on the background of dyspepsia since two years. Vomiting was bilious and nonprojectile. There was no history of abdominal pain, jaundice, hematemesis or melena. There was no history of loss of appetite or weight loss . On examination, stomach was dilated with visible peristalsis over epigastrium. There was no organomegaly. There was no palpable mass per abdomen. Upper GI endoscopy was performed which showed dilated stomach, dilated first and second part of duodenum with narrowing at D2-D3 junction (Fig. 1). CECT scan revealed sudden tapering of D2-D3 junction and no mural or intraluminal pathology in duodenum (Fig. 2). It showed associated horse shoe kidney. On exploration we found hugely dilated stomach and duodenum up to second part (Fig. 3). There was a rim of pancreatic tissue encircling whole circumference of second part of duodenum (Fig. 4). We performed Roux-en-Y end to side duodeno-jejunostomy, bypassing the obstructed segment. In the post operative period patient experienced occasional vomiting which got subsided with prokinetics. In the follow up period of 8 months, patient remained asymptomatic.

\section{Discussion}

Annular pancreas first described by Tiedemann in 1818 , is a rare congenital anomaly which most commonly manifests itself in children [2]. Patients may remain asymptomatic and present in late adulthood due to complications. 
Fig. 1 a Upper GI endoscopy showing narrowing at the D2-D3 junction. b Upper GI endoscopy showing dilated first part of duodenum

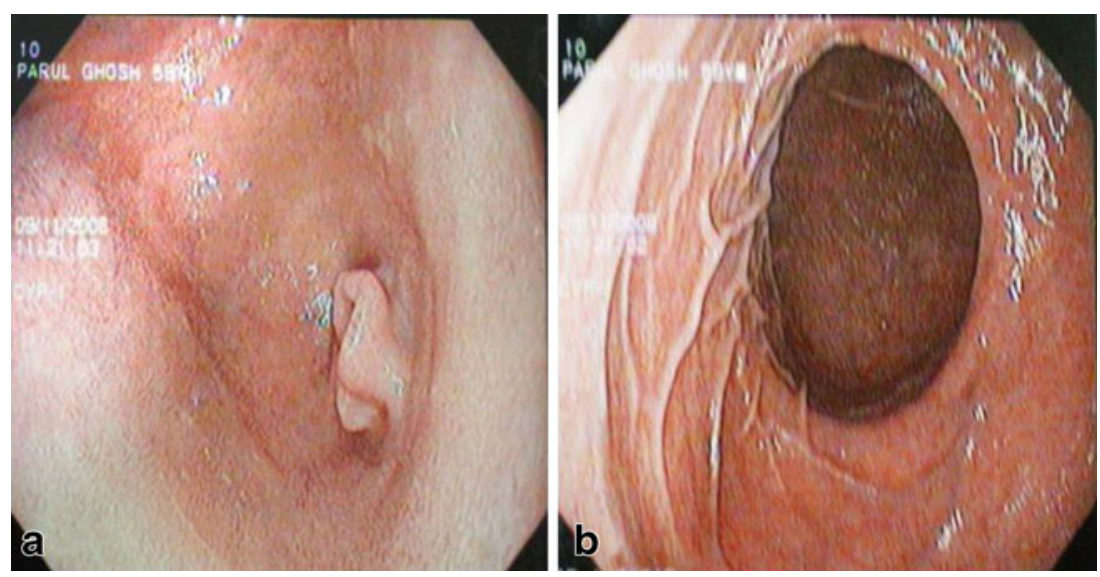

Normally pancreas develops from one dorsal and two ventral buds that first appear as evaginations of the primitive foregut at around 5th week of gestation [3]. The two ventral buds fuse early. Due to selective expansion of the duodenum by about seventh week, the ventral bud rotate with gut, passing behind the duodenum from right to left and eventually fusing with dorsal bud. Annular pancreas results from the failure of the ventral analge to rotate with the duodenum, causing envelopment of duodenum. The annulus is usually comprised of a band of pancreatic tissue, that completely encircles the second portion of the duodenum. On occasions this encirclement is incomplete leaving the anterior portion of the duodenum unconstricted. The pancreatic band is usually interspersed with the duodenal muscularis, although it can also be free from duodenum. It most commonly affects males and in up to $50 \%$ of the cases, it is associated with other congenital anomalies including down's syndrome, tracheoesophageal fistula, esophageal atresia, imperforate anus and hirschprung disease [4].

The symptoms in adults are often associated with complications of peptic ulcer, pancreatitis, duodenal obstruction and biliary obstruction [5]. Although annular pancreas may encircle the duodenum completely in adults, the food usually can pass through the duodenum without difficulty. But later in the course, secondary to chronic pancreatitis and peptic ulcer disease, it may compress and obstruct the duodenum. Preoperative diagnosis is often difficult. Imaging is of paramount importance to establish correct diagnosis. Upper GI series have been considered the study of choice. CT scan illustrates the pancreatic tissue completely or partially encircling duodenum. ERCP is specific in the diagnosis of annular pancreas which outlines pancreatic duct [6]. Around $85 \%$ of the pancreatic

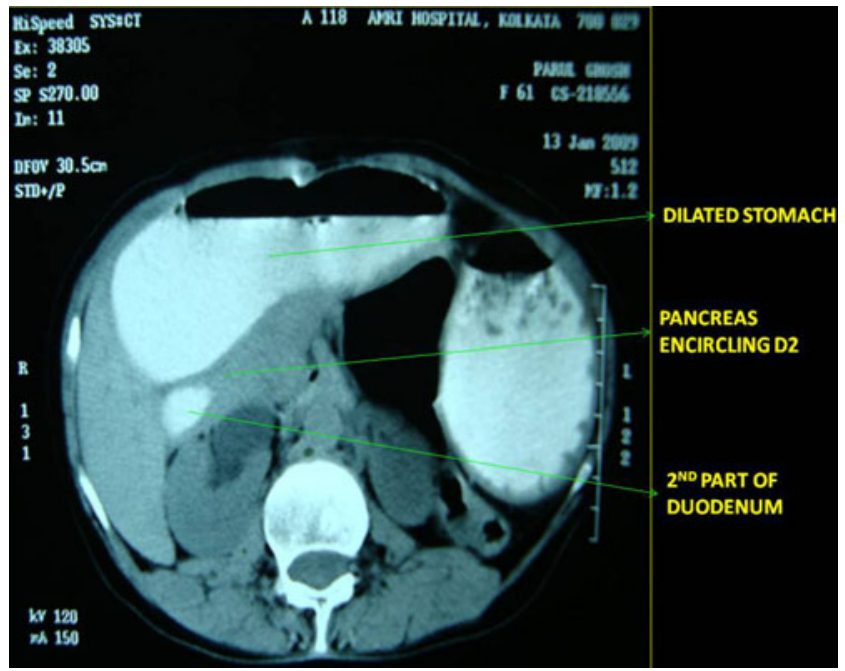

Fig. 2 Contrast Enhanced CT scan showing pancreatic tissue encircling the second part of duodenum

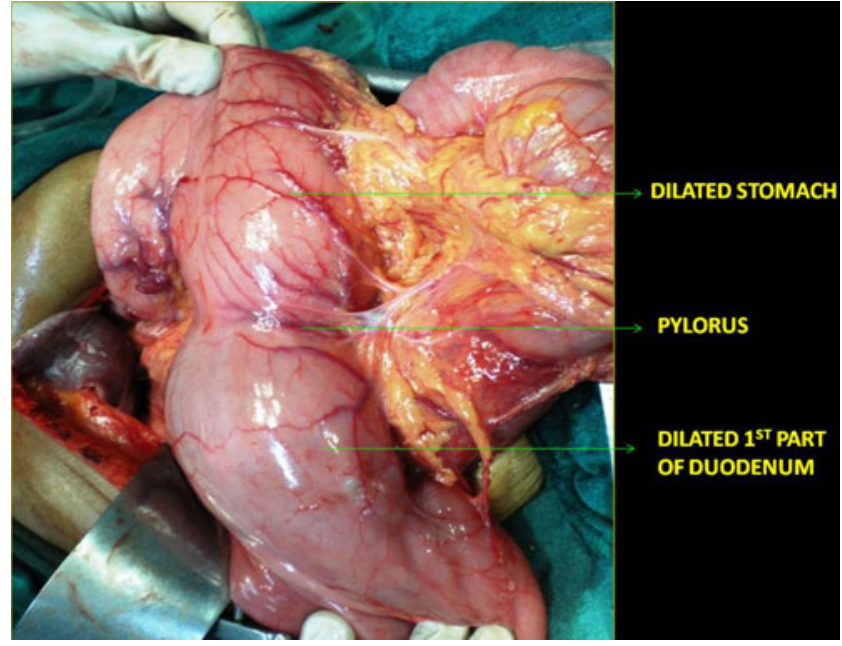

Fig. 3 Dilated stomach and first part of duodenum 


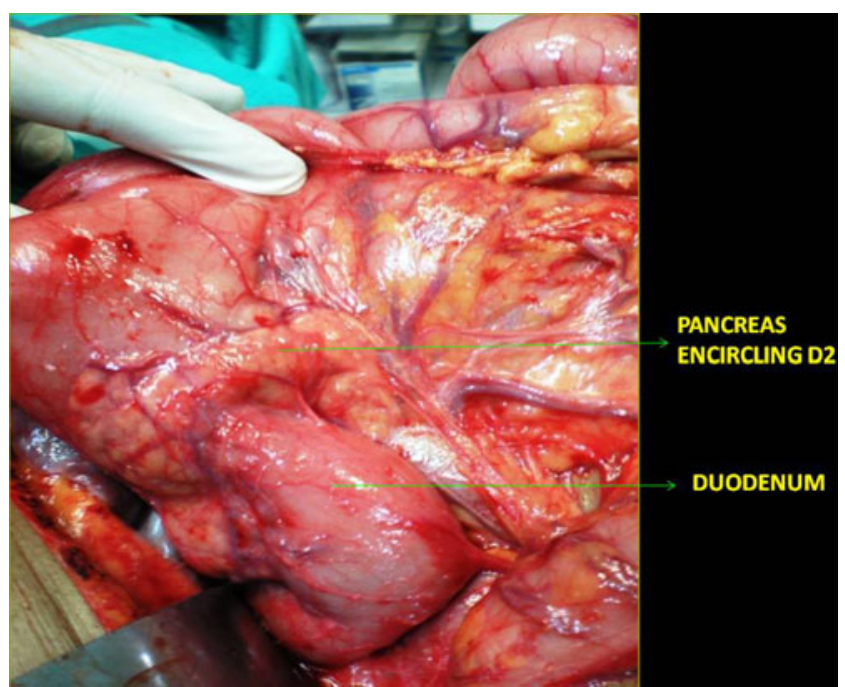

Fig. 4 Pancreatic tissue encircling the whole circumference of second part of duodenum

annular duct join the main pancreatic duct [7]. The typical appearance of annular pancreatic duct is the complete encirclement of the second portion of the duodenum. However ERCP is invasive and its indication is limited in patients with cicatrising duodenal stenosis proximal to ampulla of vater. MRCP is a non invasive method of visualising the pancreatic duct encircling the duodenum [8]. But sometimes pancreatic duct without dilation is invisible on MRCP. So surgery is still necessary to confirm the diagnosis.

Surgical bypass of the duodenum is indicated in severe stenosis. Local resection of the annular segment is avoided because of the fear of development of pancreatic fistula and is often difficult because of dense adhesions due to local fibrosis. Duodeneo-duodenostomy or duodeno-jejunostomy are the procedures of choice [9]. Gastrojejunostomy is an alternative option in case of grossly fibrotic duodenal C-loop [10].

\section{Conclusion}

To summarise, annular pancreas is one of the rare causes of duodenal obstruction in adults. Preoperative diagnosis is often difficult. CT scan, ERCP and MRCP are the imaging methods used for diagnosis. But still surgery is necessary to confirm the diagnosis and bypassing the obstructed segment $[11,12]$.

\section{References}

1. Norton KI, Tenreiro R, Rabinowitz JG (1992) Sonographic demonstration of annular pancreas and a distal duodenal diaphragm in a newborn. Pediatr Radiol 22:66-67

2. Tieddmann F (1818) Uber die Verschiedenheiten des Ausfuhrungsgangs der Bauchspeicheldruse bei den Menschen und Saugetieren. Dtsch Arch Physiol 4:403

3. Lee PC, Lebnethal E (1993) Prenatal and postnatal development of the human exocrine pancreas. In: Go VL, Dimagno EP, Gardner JD et al (eds) Pancreas: Pathology, pathobiology and disease 2nd ed. Raven Press, NY, p 57

4. Berrocal T, Torres I, Gutierrez J et al (1999) Congenital anomalies of the upper gastrointestinal tract. Radiographics 19:855-872

5. Urayama S, Kozarek R, Ball $T$ et al (1995) Presentation and treatment of annular pancreas in an adult population. Am J Gastroenterol 90:995

6. Yogi Y, Shibue T, Hashimoto S (1987) Annular pancreas detected in adults, diagnosed by endoscopic retrograde cholangiopancreatography: report of four cases. Gastroenterol Jpn 22:92

7. Li M (2002) Annular pancreas in adult. Chin J Practical Surg (Chin) 5:304-306

8. Chevallier P, Souci J, Buckley MJ et al (1999) Annular pancreas: MR imaging including MR cholangiopancreatography (MRCP). Pancreas 18:216

9. Thomford NR, Knight PR, Pace WG, Madura JA (1972) Annular pancreas in the adult: selection of operation. Ann Surg 176:159

10. De Ugarte DA, Dutson EP, Hiyama DT (2006) Annular pancreas in the adult: management with laparoscopic gastrojejunostomy. Am Surg 72:71

11. Zheng HM, Cai XJ, Shen LG, Finley R (2007) Surgical treatment of annular pancreas in adults: a report. Chin Med J (Engl) 120 (8):724-725

12. Sandrasegaran K, Patel A, Fogel EL, Zyromski NJ, Pitt HA (2009) Annular pancreas in adults. Am J Roentgenol 193(2):455-460 